\title{
Study on the Model of Creep and the Calculation of Stress Field for Concrete
}

\author{
Guo Lei ${ }^{1, *}$ and Yang Zi Sheng ${ }^{2}$
}

${ }^{I}$ College of Water Conservancy, North China University of Water Resources and Electric Power, Zhengzhou 450045, China; ${ }^{2}$ Zhongyuan University of Technology, Zhengzhou 450000, China

\begin{abstract}
The exact prediction of creep is of great significance for the simulation of the stress field of concrete creep. To overcome the limitation of the current prediction model of creep, pertinent models abroad are referred and adopted so that other factors can be controlled under standard state but only the creep varies to evaluate the feasibility of the prediction model with current characteristic of concrete materials and available test data. In the prediction of creep of high performance concrete, any influencing factor can be quantified, therefore, a large number of test data are not required. It was also observed that the defects that factors pointed out were common in the prediction model of concrete. The calculation was simple and convenient and achieved a higher accuracy. In the calculation of creep stress field, the creep was calculated according to fitting creep degree. Based on this, this paper established the creep coefficient formulas for the calculation of strain increment, and deduced the number of finite element expressions which were used to calculate the creep stress field with creep coefficient.
\end{abstract}

Keywords: Creep coefficient, high-performance concrete, nonstandard state, prediction model, standard state.

\section{INTRODUCTION}

The calculation formulas for Creep coefficient are all empirical formulas, which are based on the empirical data. Due to the limitations of experimental conditions and the difference of emphasis, computation modules proposed by different researchers contain different influential factors. The commonly used models are: CEB-FIP [1], ACI209 [1], B-P [2], GZ (1993) [3] and GL-2000 [4]. The representative model in China is provided by China's Academy of Building Research (1986) [5]. In the 1990s, Weijun [6] et al. set up the creep estimation system of concrete in dry areas based on CEB-FIP (1990) framework, and the system worked well according to test results. Wu Shengxin, according to the analysis of the data of creep test on 17 groups of dam concrete, proposed the mathematical model used to estimate hydraulic big volume concrete creep in hydraulic engineering. Among current prediction models of creep, characteristics of the concrete were obtained by regression analysis of lots of test data, and the characteristics indicated the regularity of the concrete creep-development. However, concrete is a kind of artificial-composite material. Big difference exists in the characteristics of concrete of different projects, and in the effects of creep. This is the main reason why the current prediction models cannot obtain satisfied prediction results.

The author tried to take into account different factors caused by different materials and other factors influencing the performance of concrete, and designed the HPC creep

\footnotetext{
*Address correspondence to this author at the College of Water Conservancy, North China University of Water Resources and Electric Power. Zhengzhou 450045, China: Tel: +8613525587730 ;

E-mail: glboss@126.com
}

coefficient formula based on the NSC standard. The model adopted the spreading models of CEN Euro code 2 (1991) and CEB Model 90 (1993); generated the sample data of creep coefficient under standard conditions according to the calculation results of creep coefficients provided by the improved CEB model (1993), and further designed the creep coefficient formula under the standard state. Compared with the creep coefficient model of ordinary concrete, all the influencing factors were numerical in the model, and the model was capable to forecast the creep of high-performance concrete precisely even without large amount of test data.

This article is divided into two parts. In the first part, the creation of the creep coefficient prediction model for Chinese Concrete materials is illustrated with the model's diagnosis. In the second part, the creep coefficient was imported into the formula for calculating the incremental strain, and the expression of creep finite element stress field was derived using creep coefficient.

\section{BASIC EQUATIONS OF CREEP COEFFICIENT UNDER STANDARD STATE}

The "standard state" in this paper was different from the "standard state" recommended by the United States Concrete Association (ACI) 209 Committee. The creep tests of compression and tension, do not involve the provisions of the environmental humidity involved in China's power industry standard DL/T 5150-2001 "hydraulic concrete test order", combined with China's normative GBJ 82-85 for long-term performance of ordinary concrete and the durability of test method". The standard state has concrete strength grade C30. Fly ash and admixtures are not mixed, and crosssection size of Cube specimens is $150 \mathrm{~mm} \times 150 \mathrm{~mm}$. 
After 3d's standard curing, creep test was carried out in the constant temperature and humidity at room (temperature $20 \pm 2{ }^{\circ} \mathrm{C}$, with relative humidity $60 \pm 5 \%$ ). Loading creep stress resulted in damage load for the sample of $30 \%$, suggesting the stress level of 0.3 .

The practical considerations in the prediction of creep involved, the starting time of loading of concrete which is the major component variable of creep coefficient. Under the standard state, the basic equation of creep coefficient is as follows:

$$
\phi(\mathrm{t}, \tau)_{\text {basic }}=\phi(\infty, 3) k_{\tau}
$$

Where $\phi(\infty, 3)$ is the creep coefficient under the standard state; loading age is $\mathrm{t}_{0}=3 \mathrm{~d}$; holding time can be infinitude; $k \tau$ is the influence function of holding time; and $\tau=\mathrm{t}-\mathrm{t}_{0}$ is the holding time.

\subsection{The Regression Analysis of Creep Coefficient Sample Data under Standard State}

According to calculation results of creep coefficient provided by spreading model, the database of creep coefficient under standard state was created to fit the creep coefficient used in the study under the standard state. The brief form of basic equation of the spreading model which belongs to European norms is as follows:

$$
\phi\left(t, t_{0}\right)=\phi_{0} \beta_{c}\left(t, t_{0}\right)
$$

where $\phi\left(t, t_{0}\right)$ is the load of concrete at $t_{0} ; \beta_{c}\left(t, t_{0}\right)$ is the creep coefficient at $\mathrm{t} ; \varphi_{0}$ is the nominal creep coefficient:

$$
\begin{aligned}
& \beta_{c}\left(t, t_{0}\right)=\left[\left(t-t_{0}\right) /\left(\beta_{H}+t-t_{0}\right]^{0.3}\right. \\
& \beta_{H}=1.5\left[1+(0.012 g R H)^{18}\right] g h_{0}+250 \alpha_{3} \leq 1500 \alpha_{3}
\end{aligned}
$$

where RH is the environmental relative humidity, \%; $\mathrm{h}_{0}=2 \mathrm{~A}_{\mathrm{c}} / \mathrm{u} ; \mathrm{A}_{\mathrm{c}}$ is the cross-section of component $\left(\mathrm{mm}^{2}\right) ; \mathrm{u}$ is the length of component touching environment; $\alpha_{i}$ is the coefficient dependent on the average compressive strength of concrete.

The advantages and limitations of spreading model are as follows:

(1) The CEB model (1990) is not clearly divided into the basic creep and drying creep but it is a simplified method. It is important for applying the spreading model to the field of high performance concrete. Being a suitable model, it is worth referring to,

(2) The spreading model has a wide application because it introduced three coefficients of compressive strength that are suitable for the general strength of concrete. For this reason, it remains to be verified.

(3) The limitation of the model is that, a 28-day compressive strength characteristic of high-performance concrete is the sole factor considered in the model. Other factors such as silica fume, fly ash type and quantity are not considered. Hence, it is very similar to the concept model.

According to the calculated results, the approximate loading of $11520 \mathrm{~d}$ days is used as the terminal value for the creep coefficient, and the value of $\phi(t, 3) / \phi(11520,3)$ is used as the coefficient of holding impact $k_{\tau}$, as shown in Fig. (1).
According to the data characteristic, a formula was designed for an exponential function: $y=1-a \times E X P(-b \times \tau)$ and the result of regression was:

$$
y=1-0.72 \operatorname{EXP}(-0.006 \tau), R S q=0.953
$$

Where, $\mathrm{RSq}$ is the square of the regression correlation coefficient which is used to measure the superiority of regression mode. The more close the value of $\mathrm{RS}_{\mathrm{q}}$ is to 1 , the more superior is the model. Based on the above analysis, the basic state was obtained, and the basic form of equation of creep coefficient is as follows:

$$
\begin{aligned}
& \phi(\mathrm{t}, 3)_{\text {basic }}=\phi(\infty, 3) \times k_{\tau} \\
& =3.7419\{1-0.72 \operatorname{EXP}[-0.006(t-\tau)]\}
\end{aligned}
$$

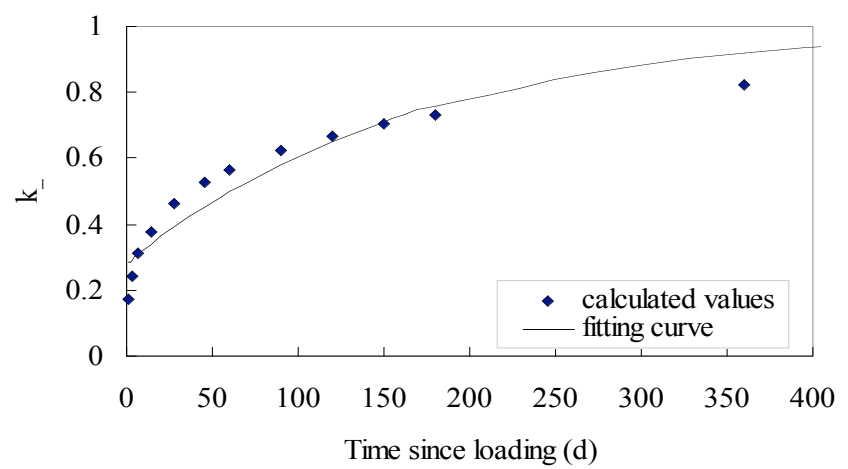

Fig. (1). The relation of load ages and the creep coefficient under different loading ages.

\subsection{The Design of Creep Coefficient under Non-standard State}

Many factors affect concrete creepand they contact each other as well as restrict each other. The law is concluded based on the results of a large amount of data. The significant factors include load duration, loading age, the characteristic of basic materials that compose concrete (including the cement variety, the aggregate variety, water-cement ratio etc.), admixture, fly ash content, volume-surface areas ratio of component, environmental relative humidity, curing condition, and environmental temperature.

The effect of load duration is considered under standard state. The characteristics of basic materials that compose concrete are measured by concrete strength. Other factors (nine in total) have different impacts on the function. It is very complex to analyze nonlinear influence of the multivariate and multi-level. Therefore, when determining the effect of a certain factor on the concrete creep function, the method only changes the factor (all factors are independent of each other) and keeps the other factors in the standard state.

\subsubsection{Loading Age}

The mechanical properties of concrete are different under different loading age, therefore, research is required to further study the effect of the loading age on creep. When other factors are maintained in the standard state, and the longer the loading age, the smaller the creep . Therefore, when load duration $\tau$ tends to be infinite, the loading age tends to be 
long, the creep tends to be small, and the extreme values change slowly. The creep coefficient was calculated under seven different load ages and load duration was also calculated by the spreading model. Moreover, the creep coefficient of other six loading ages was calculated based on 3d's loading age. Results are shown in Table 1. From Table 1, it can be observed that for a given loading aget 0 , the effect of loading age on creep coefficient was not obvious under different load durations. But for the same load duration $\tau$, the creep coefficient was more sensitive to the loading age t0. The relation graph of the average value of relative creep coefficient under different load duration and the loading age is shown in Fig. (2). The influence function of loading age t0 decreased (the first-order derivative is less than zero), and the second-order derivative was greater than zero.

To reflect this characteristic, the influence function corresponded to the average value of relative creep coefficient under different load duration. And the influence function of loading age is as follows :

$\beta\left(t_{0}\right)=0.008+0.99\left(\frac{3}{t_{0}}\right)^{0.195}$

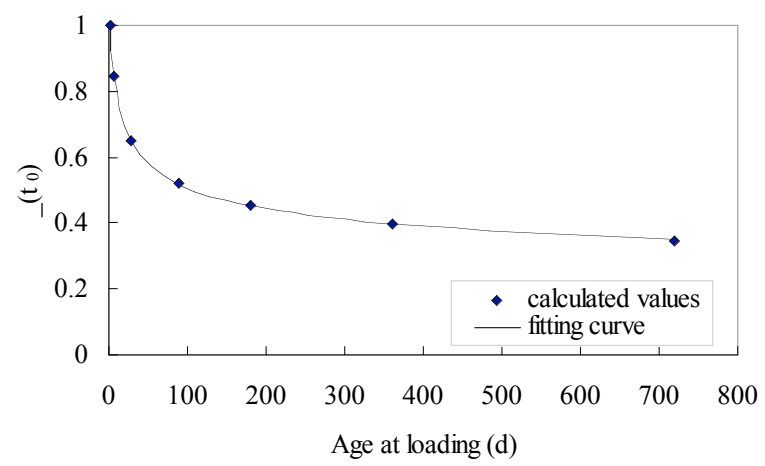

Fig. (2). The relation of load ages and the creep coefficient average under different loading duration.

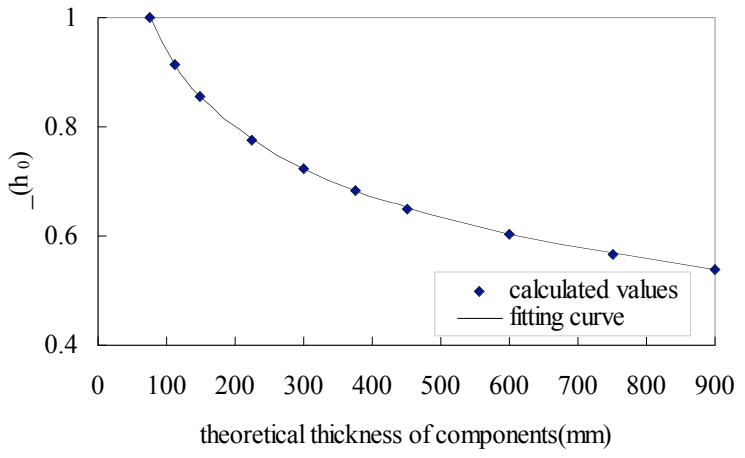

Fig. (3). The relation of concrete depth and the creep coefficient average under different loading duration.

\subsubsection{The Dimension of Component}

The effect of concrete shape and dimension on shrinking the creep in terms of volume-surface area ratio met the requirements of actual projects. The calculation results obtained by the spreading model were sufficiently close to the test results of concrete creep. The relative value of creep coefficient (that is influence coefficient of component theoretical thickness) with different theoretical thickness $\left(\mathrm{h}_{0}\right)$ and different load duration $\left(\mathrm{t}-\mathrm{t}_{0}\right)$ was calculated. It's worth mentioning that other factors were in the standard state defined in this paper, and $\mathrm{h}_{0}$ was equal to $75 \mathrm{~mm}$ under the same load duration, which is a standard state. The relation graph of the influence coefficient of component theoretical thickness and component theoretical thickness is shown in Fig. (3).

\subsubsection{The Influence Coefficient of Strength Grade}

The creep coefficient in ACI209 mode、GL2000 model did not clearly consider the effect of concrete strength grade. Therefore, it did not meet the test result. The forecast results of high-performance concrete were not ideal, and need to be amended.

The creep of concrete is inversely proportional to the square root of the average value of 28-day cylinder compressive strength in CEB-FIP (1990) model. Later, the evolutionspreading model used this model.

The author determined the strength-influence function by the data sample of calculated value of China's ordinary concrete strength grade C20 C70 based on the CEB-FIP (1990) model of strength-influence function and the relative value of strength-influence coefficient based on concrete C30, as shown in Table 1. Strength-influence function with reference to CEB-FIP (1990) model is shown as follows :

$\beta\left(f_{c m}\right)=16.8 / f_{c m}^{1 / 2}$

$\mathrm{fcm}$ - average compressive strength; $\mathrm{fcm}=\mathrm{fck}+8(\mathrm{Mpa})$, fck- characteristic strength $; \beta(\mathrm{fck})=(30 / \mathrm{fck}) \mathrm{a}$.

Table 1. Influencing coefficient of concrete strength.

\begin{tabular}{|c|c|c|c|c|c|c|c|}
\hline$f_{\text {ck }}$ & 20 & 30 & 40 & 50 & 55 & 60 & 70 \\
\hline$f_{\mathrm{cm}}$ & 28 & 38 & 48 & 58 & 63 & 68 & 78 \\
\hline$\beta\left(f_{\mathrm{cm}}\right)$ & 3.175 & 2.725 & 2.425 & 2.206 & 2.117 & 2.037 & 1.902 \\
\hline$\beta\left(f_{\mathrm{ck}}\right)$ & 1.165 & 1.00 & 0.890 & 0.809 & 0.777 & 0.748 & 0.698 \\
\hline
\end{tabular}

After fitting by SPSS analysis software and by determining coefficient $\alpha=0.411$, residual standard deviation was observed to be 0.006 and correlation coefficient was 0.998 , therefore:

$$
\beta\left(f_{c k}\right)=\left(30 / f_{c k}\right)^{0.411}
$$

\subsubsection{The Influence Coefficient of Curing Temperature}

At present, the analysis of structural-temperature stress does not take into account environmental temperature effect on the concrete creep. But the study showed that creep deformation is linked with curing temperature. Different curing temperature lends to different creep. By quoting the research data of former Soviet Union, the formula of environment influence coefficient $\beta_{\mathrm{T}}$ is shown as follows:

$\left.\begin{array}{l}\beta_{T}=c(t, T) / c\left(t, T=20^{\circ}\right) \\ \beta_{T}=0.56+0.022 T\end{array}\right\}$ 
Formula shows that the general curing temperature was $20^{\circ} \mathrm{C}$ (standard state). When curing temperature was $\mathrm{T}=30$ ${ }^{\circ} \mathrm{C}$, then $\beta \mathrm{T}=1.22$, and creep degree increased to $22 \%$. However, when $\mathrm{T}=40{ }^{\circ} \mathrm{C}$, then $\beta \mathrm{T}=1.44$, and creep degree increased to $22 \%$.

\subsubsection{The Coefficient of Admixture}

In actual project, especially in the field of pumping concrete, widely used admixtures include water reducing agent and air-entraining agent. They play a significant role in increasing strength, concrete workability, frost resistance, cement saving and adjusting the time of setting . According to ACI209R(1992) model, the effect of slump constant on creep can be amended by following formula:

$\beta=0.82+0.00264 S_{f}$

Where, Sf is slump constant (mm). According to the result of this formula, creep added water reducing agent increased to $15 \% \sim 30 \%$ (ordinary water reducing agent) and $20 \% \sim 40 \%$ (high efficient water reducing agent). Airentraining agent resulted in increasing creep. Generally, the suitable adding content of MPA is $0.005 \% \sim 0.015 \%$ of the cement weight in order for the suitable air content of concrete to be up to $3 \sim 6 \%$. The effect of air content on the creep of concrete is amended by the formula as follows:

$\beta=0.46+0.09 a$

Where, a is the air content, in percentage form. According to the result of this formula, creep increased to $20 \%$ $40 \%$ after adding air-entraining agent. The effect of admixture on creep test data was little, due to the fact that water reducing agent and air-entraining agent were added at the same time. It can be amended according to the variety and mixing amount, if necessary, by experimental investigation as shown in Fig. (4).

To sum up, the effect of admixture on concrete creep was amended by correction coefficient, shown in Table 2.

Table 2. Correction coefficient $\beta$ a of admixture.

\begin{tabular}{|c|c|c|c|}
\hline $\begin{array}{c}\text { The type of ad- } \\
\text { mixture }\end{array}$ & $\begin{array}{c}\text { Ordinary water } \\
\text { reducing agent }\end{array}$ & $\begin{array}{c}\text { High- efficient } \\
\text { water reducing } \\
\text { agent }\end{array}$ & $\begin{array}{c}\text { air-entraining } \\
\text { agent }\end{array}$ \\
\hline \hline $\begin{array}{c}\text { Correction } \\
\text { coefficient }\end{array}$ & $1.15 \sim 1.30$ & $1.20 \sim 1.40$ & $1.20 \sim 1.40$ \\
\hline
\end{tabular}

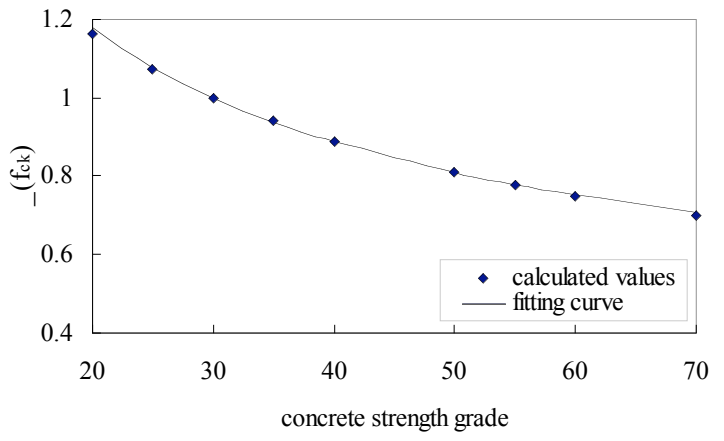

Fig. (4). Correction coefficient $\beta_{\text {fck }}$ of concrete strength.

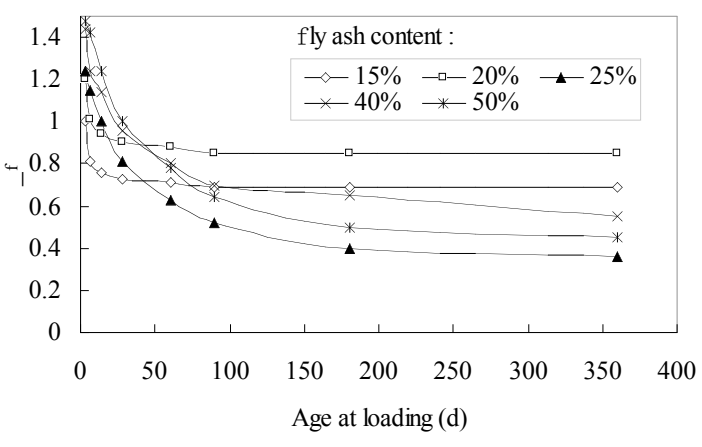

Fig. (5). Correction coefficient $\beta_{\mathrm{f}}$ of fly ash.

\subsubsection{The Influence Coefficient of Fly Ash}

In this study $t$, the fly ash concrete test data was not conducted. Basically, the existing research aimed at ordinary concrete. It is difficult to quantify the correction coefficient accurately. According to the engineering test, the correction coefficient $\beta_{f}$ of fly ash can be determined according to Fig. (5).

\section{VERIFICATION OF THE NEW PREDICTION MODEL}

To sum up, the creep coefficient of the common concrete in the non-standard state can be calculated as the following formula:

$$
\phi\left(t, t_{0}\right)=\phi\left(t, t_{0}\right)_{\text {basic }} \cdot \beta\left(t_{0}\right) \beta\left(h_{0}\right) \beta\left(f_{c k}\right) g \beta_{T} \beta_{f} \beta_{a}
$$

This article selected and used four sets of actually measured data of creep test [7-10] and compared them with the prediction model, CEB-FIP (1990) model, and GL2000 model, respectively as shown in Figs. (6-9). There are some differences between the calculated values and the observed values of all the models, in which the calculation error of the CEB-FIP (1990) model was maximal. In the model used in this study, the value approximated better with the observed value and the law was similar to other models and the precision was somewhat improved and the relative error of the creep coefficient calculation in all ages was less than 10 percent. In the prediction of the creep of high performance concrete, the model can quantify each influencing factor, and supplements the defect that the factors considered in common prediction model are relatively simple. Not only the calculation is simple, but also the precision of fitting is better.

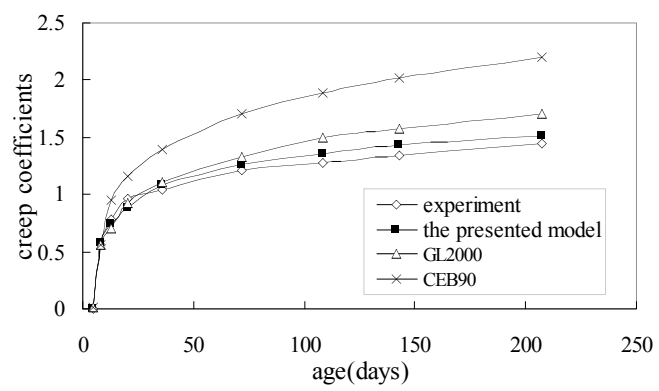

Fig. (6). Comparison between measured creep coefficient from 7 refs and fitted value by equation. 


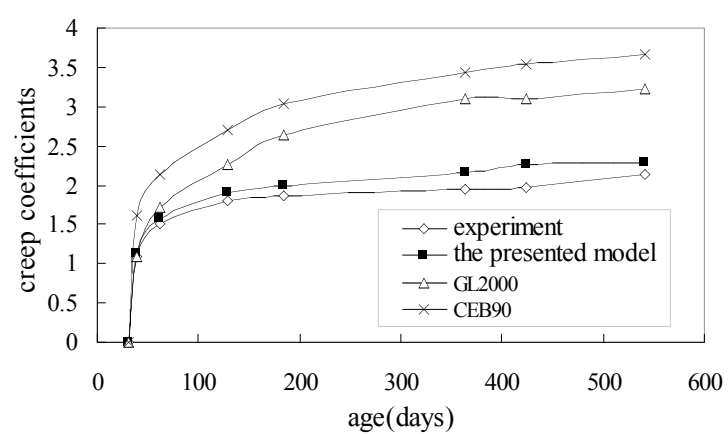

Fig. (7). Comparison between measured creep coefficient from 8 refs and fitted value by equation.

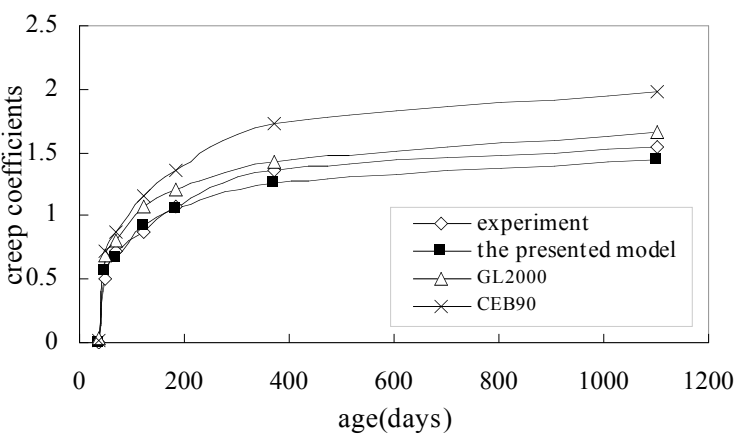

Fig. (8). Comparison between measured creep coefficient from 9 refs and fitted value by equation.

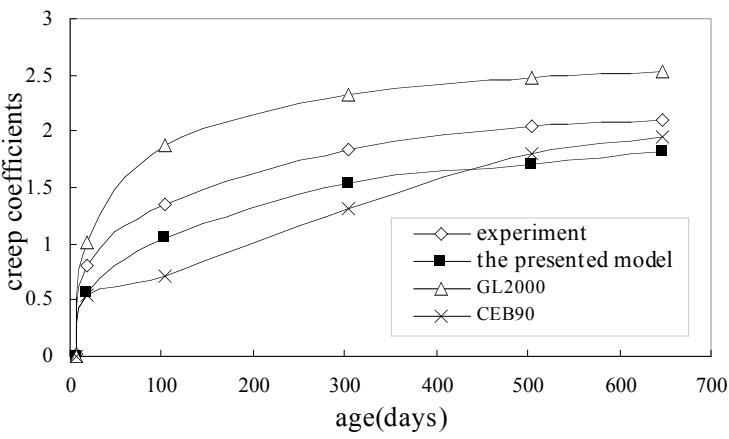

Fig. (9). Comparison between measured creep coefficient from 10 refs and fitted value by equation.

\section{THE CALCULATION DERIVATION OF CREEP INCREMENTS}

Because the creep of concrete is related to both the current stress and the historical stress, the calculation was performed by considering the stress history. Therefore, to limit the size of the memory of the computer when analyzing the concrete structure is difficult.. For determining the creep degree expressed in exponential function, Zienkiewicz et al. came up with an explicit method based on equal step length and Zhu Bofang Academician gave the idea of the implicit method. On the basis of this method, this paper introduced the formula of creep coefficient used for the calculation of strain increment and deduced the implicit method of creep equation expressed in creep coefficient. Loading from to to t, the strain of concrete creep is deduced as:

$$
\begin{aligned}
& \varepsilon^{c}(t)=\Delta \sigma_{0} C\left(t, \tau_{0}\right)+\int_{\tau_{0}}^{t} C(t, \tau) d \sigma \\
& =\Delta \sigma_{0} C\left(t, \tau_{0}\right)+\sum_{i} \int_{\tau_{i-1}}^{\tau_{i}} C(t, \tau) \frac{d \sigma}{d \tau} d \tau \\
& =\Delta \sigma_{0} C\left(t, \tau_{0}\right)+\sum_{i}\left(\frac{d \sigma}{d \tau}\right)_{i} \int_{\tau_{i-1}}^{\tau_{i}} C(t, \tau) d \tau
\end{aligned}
$$

When the timestep length is not too long, according to the integral mean value theorem, the creep degree $C\left(t, \tau_{i}\right)$ of mid-point age is used to replace $C(t, \tau)$, to obtain the following formula:

$$
\begin{aligned}
& \varepsilon^{c}=\Delta \sigma_{0} C\left(t, \tau_{0}\right)+\sum_{i}\left(\frac{d \sigma}{d \tau}\right)_{i} C\left(t, \overline{\tau_{i}}\right) \Delta \tau_{i} \\
& =\Delta \sigma_{0} C\left(t, \tau_{0}\right)+\sum_{i} C\left(t, \overline{\tau_{i}}\right) \Delta \sigma_{i}
\end{aligned}
$$

According to the relational expression between creep coefficient and creep degree : $\phi(t, \tau)=C(t, \tau) E(\tau)$ then :

$C(t, \tau)=\frac{\phi(t, \tau)}{E(\tau)}$

According to the creep coefficient formula designed in this paper, the serial number of the former text is directly quoted.

$\phi(t, \tau)=\phi(t-\tau, 3)_{\text {basic }} \cdot \beta(\tau) \beta\left(h_{0}\right) \beta\left(f_{c k}\right)$

. $\beta(R H) \beta_{T} \beta_{f} \beta_{a}$

For the particular concrete and curing condition,

$\beta\left(h_{0}\right), \beta\left(f_{c k}\right), \beta(R H), \beta_{T}, \beta_{f}, \beta_{a}$ is a constant value,

$\beta=\beta\left(h_{0}\right) \beta\left(f_{c k}\right) \beta(R H) \beta_{T} \beta_{f} \beta_{a}$

According to the foregoing formula:

$\phi(\mathrm{t}-\tau, 3)_{\text {basic }}=\phi(\infty, 3) \times K_{(t-\tau)}$

$=3.7419\{1-0.72 \exp [-0.006(t-\tau)]\}$

$\beta(\tau)=e^{\left[-0.148(\tau-3)^{0.312}\right]}$

Put formula (19) into formula (15) then obtain :

$C(t, \tau)=\frac{\beta(\tau) \beta}{E(\tau)} \phi(t-\tau, 3)_{b a s i c}$

By substituting formula (20) into formula (23) following equation is obtained:

$\varepsilon^{c}(t)=\Delta \sigma_{0} \frac{\beta\left(\tau_{0}\right) \beta}{E\left(\tau_{0}\right)} \phi\left(t-\tau_{0}, 3\right)_{\text {basic }}=\Delta \sigma_{0} \frac{\beta\left(\tau_{0}\right) \beta}{E\left(\tau_{0}\right)} 3.7419\left[1-0.72 e^{-0.006\left(t-\tau_{0}\right)}\right]$
$+\sum_{i} \frac{\beta\left(\overline{\tau_{i}}\right) \beta}{E\left(\bar{\tau}_{i}\right)} \phi\left(t-\bar{\tau}_{i}, 3\right)_{b a s i c} \Delta \sigma_{i} \quad+\sum_{i} \frac{\beta\left(\overline{\tau_{i}}\right) \beta}{E\left(\bar{\tau}_{i}\right)} 3.7419\left[1-0.72 e^{-0.0006\left(-\overline{\tau_{i}}\right)}\right] \Delta \sigma_{i}$

By selecting the third adjacent time $t_{n+1} 、 t_{n} 、 t_{n-1}$, timestep is according to $\Delta \tau_{n}=t_{n}-t_{n-1}, \Delta \tau_{n+1}=t_{n+1}-t_{n}$, and the following is obtained:

$$
\begin{aligned}
& \varepsilon_{n+1}^{c}=\Delta \sigma_{0} \frac{\beta\left(\tau_{0}\right) \beta}{E\left(\tau_{0}\right)} 3.7419\left[1-0.72 e^{-0.000\left(t_{n+1}-\tau_{0}\right)}\right] \\
& +\sum_{i}^{n+1} \frac{\beta\left(\overline{\tau_{i}}\right) \beta}{E\left(\bar{\tau}_{i}\right)} 3.7419\left[1-0.72 e^{-0.0006\left(t_{n+1}-\bar{\tau}_{i}\right.}\right] \Delta \sigma_{i}
\end{aligned}
$$


$\varepsilon_{n}^{c}=\Delta \sigma_{0} \frac{\beta\left(\tau_{0}\right) \beta}{E\left(\tau_{0}\right)} 3.7419\left[1-0.72 e^{-0.006\left(t_{n}-\tau_{0}\right)}\right]$

$+\sum_{i}^{n} \frac{\beta\left(\overline{\tau_{i}}\right) \beta}{E\left(\overline{\tau_{i}}\right)} 3.7419\left[1-0.72 e^{-0.006\left(t_{n}-\bar{\tau}_{i}\right)}\right] \Delta \sigma_{i}$

$\varepsilon_{n-1}^{c}=\Delta \sigma_{0} \frac{\beta\left(\tau_{0}\right) \beta}{E\left(\tau_{0}\right)} 3.7419\left[1-0.72 e^{-0.006\left(t_{n-1}-\tau_{0}\right)}\right]$

$+\sum_{i}^{n-1} \frac{\beta\left(\overline{\tau_{i}}\right) \beta}{E\left(\overline{\tau_{i}}\right)} 3.7419\left[1-0.72 e^{-0.006\left(t_{n-1}-\bar{\tau}_{i}\right)}\right] \Delta \sigma_{i}$

Subtract the formula (22) with (23) then obtain:

$\Delta \varepsilon_{n+1}^{c}=\Delta \sigma_{0} \frac{\beta\left(\tau_{0}\right) \beta}{E\left(\tau_{0}\right)} 2.694\left[e^{-0.006\left(t_{n}-\tau_{0}\right)}-e^{-0.006\left(t_{n}+\Delta \tau_{n+1}-\tau_{0}\right)}\right]$

$+\sum_{i}^{n} \frac{\beta\left(\overline{\tau_{i}}\right) \beta}{E\left(\overline{\tau_{i}}\right)} 2.694\left[e^{-0.006\left(t_{n}-\bar{\tau}_{i}\right)}-e^{-0.006\left(t_{n}+\Delta \tau_{n+1}-\bar{\tau}_{i}\right)}\right] \Delta \sigma_{i}$

$+\frac{\beta\left(\overline{\tau_{n+1}}\right) \beta}{E\left(\overline{\tau_{n+1}}\right)} 3.7419\left[1-0.72 e^{-0.006\left(t_{n}+\Delta \tau_{n+1}-\overline{\tau_{n+1}}\right)}\right] \Delta \sigma_{n+1}$

$\psi(\tau)=\frac{\beta(\tau) \beta}{E(\tau)} 2.694$ as:

By substituting formula (26) into (25), (26) is simplified

$\Delta \varepsilon_{n+1}^{c}=\left(1-e^{-0.006 \Delta \tau_{n+1}}\right)\left\{\Delta \sigma_{0} \psi\left(\tau_{0}\right) e^{-0.006\left(t_{n}-\tau_{0}\right)}\right.$

$\left.+\sum_{i}^{n} \Delta \sigma_{i} \psi\left(\overline{\tau_{i}}\right) e^{-0.006\left(t_{n}-\bar{\tau}_{i}\right)}\right\}$

$+\frac{\beta\left(\overline{\tau_{n+1}}\right) \beta}{E\left(\overline{\tau_{n+1}}\right)} 3.7419\left[1-0.72 e^{-0.006\left(t_{n}+\Delta \tau_{n+1}-\overline{\tau_{n+1}}\right)}\right] \Delta \sigma_{n+1}$

Using the same argument, by subtracting the formula (23) with (24), the following equation is obtained :

$$
\begin{aligned}
& \Delta \varepsilon_{n}^{c}=\left(1-e^{-0.006 \Delta \tau_{n}}\right)\left\{\Delta \sigma_{0} \psi\left(\tau_{0}\right) e^{-0.006\left(t_{n}-\Delta \tau_{n}-\tau_{0}\right)}\right. \\
& \left.+\sum_{i}^{n-1} \Delta \sigma_{i} \psi\left(\overline{\tau_{i}}\right) e^{-0.006\left(t_{n}-\Delta \tau_{n}-\overline{\tau_{i}}\right)}\right\} \\
& +\frac{\beta\left(\overline{\tau_{n}}\right) \beta}{E\left(\overline{\tau_{n}}\right)} 3.7419\left[1-0.72 e^{-0.006\left(t_{n}-\overline{\tau_{n}}\right)}\right] \Delta \sigma_{n}
\end{aligned}
$$

Through the two expressions of (6-77) and (6-78) recursion formula is obtained :

$$
\Delta \varepsilon_{n}^{c}=\left(1-e^{-0.006 \Delta \tau_{n}}\right) \vartheta_{n}+\Delta \sigma_{n} C\left(t_{n}, \overline{\tau_{n}}\right)
$$

Where

$$
\begin{aligned}
& \vartheta_{n}=\vartheta_{n-1} e^{-0.006 \Delta \tau_{n-1}}+\Delta \sigma_{n-1} \psi\left(\overline{\tau_{n-1}}\right) e^{-0.003 \Delta \tau_{n-1}}, \\
& \vartheta_{1}=\Delta \sigma_{0} \psi\left(\tau_{0}\right)
\end{aligned}
$$

This set of recursion formulas does not need to record the stress history, rather it only needs to store sita when the concrete structure is analyzed with the numerical method.

\section{CONCLUSION}

Properly predicting the creep model of high performance concrete is very important for designing and construction.
For this reason, penman did some exploration about how to develop a set of formulas of creep prediction model that are convenient, practical and give consideration to certain precision of prediction. Some steps are discussed as follows:

(1) The setting of the standard state strengthens the commonality of different tests and can utilize the available test data better. According to the calculation and comparison, the formulas of creep coefficient model suggested in this paper have the characteristic of practical utility and consideration of certain precision.

(2) Penman considered more comprehensively the influence of various factors on the creep, and supplemented the deficiency of creep prediction model of common concrete. On the standard state basis, the influence function was accurate, which made the formulas of creep coefficient more feasible .

(3) With a lack of tests, not only the creep of common concrete can be predicted, but also it can be simply estimated with certain accuracy according to the material and the circumstance of high performance concrete and the calculation formulas in non-standard state.

(4) In the calculation of creep stress field, the implicit method is usually adopted which calculates the creep according to the fitting creep degree. On this basis, this paper introduced the creep coefficient formulas designed for the calculation of strain increment, and deduced the finite element expression by calculating the creep stress field with the creep coefficient, which did not require calculating the stress period.

\section{CONFLICT OF INTEREST}

The authors confirm that this article content has no conflict of interest.

\section{ACKNOWLEDGEMENTS}

This work was supported by the National natural science foundation of China (No. 51109081).

\section{REFERENCES}

[1] ACI Committee 209. "Prediction of Creep, Shrinkage and Temperature Effects in Concrete Structures," Manual of concrete practice, Part 1. American Concrete Institute, 1992.

[2] F.J. Ulm, Z. P. Bazant, and F.H. Wittman, "Creep, shrinkage and durability mechanics of concrete and other quasi-brittle materials", Elsevier Science, Amsterdam, Netherland, 2011.

[3] N.J. Gardner, and J. W. Zhao, "Creep and shrinkage revisited," $A C I$ Mater. J., vol. 90, pp. 236-246, 1993.

[4] N. J., Gardner, and M.J. Lockman, "Design provisions for drying shrinkage and creep of normal-strength concrete," ACI Mater. J., vol. 98, pp. 159-167, 2001.

[5] L. S. Gong, M. Y. Hui, and B. Yang, "Practical mathematical expressions for creep and shrinkage of concrete," J. Build. Struct., vol. 9, pp. 37-41, 1988. (in Chinese)

[6] J. Wei, and H. J. Zhao, "Prediction for concrete shrinkage and creep in extreme dry areas," J. Huazhong U. Sci-Med., vol. 29, pp. 109-110, 2001. (in Chinese)

[7] J. X. Zou, X. J. Li, and P. Y. Chi, "A research of deformation of Fly Ash Concrete," Concrete, vol. 6, pp. 38-39, 2003. (in Chinese)

[8] L. B. Pan, and S. J. Zhang, "Prediction of shrinkage and creep in concrete," J. Hohai. U., vol. 25, pp. 84-89, 1997. ( in Chinese) 
[9] Z.F. Yin, "Relationship between strength grade and shrinkage of concrete," Concrete, vol. 6, pp. 21-23, 1991. (in Chinese)
[10] H. X. Yao, Z. Q. Chen, and X. D. Tang, "Test analysis of the creeping of high-performance concrete," J. Cent. South Forest. U., vol. 26, pp. 113-116, 2006. (in Chinese)

Received: February 03, 2015

Revised: April 03, 2015

Accepted: May 25, 2015

(C) Lei and Sheng; Licensee Bentham Open.

This is an open access article licensed under the terms of the (https://creativecommons.org/licenses/by/4.0/legalcode), which permits unrestricted, noncommercial use, distribution and reproduction in any medium, provided the work is properly cited. 